\title{
La posta de narradores o el arte de narrar en J. C. Onetti
}

\author{
Maximiliano Linares
}


PALABRA CLAVE

Onetti, posta de narradores, realismo, narrativa latinoamericana.

KEYWORDS

Onetti, narrator's relay, Realism Latin-American narrative.

\section{RESUMEN}

En este trabajo intentamos desarrollar la categoría de la posta de narradores en la escritura del uruguayo Juan Carlos Onetti a partir del análisis de los procedimientos aplicados en tres de sus narraciones de la década del '50. En base a estas instancias narratológicas ("El álbum", 1953; Los adioses, 1954; y Para una tumba sin nombre, 1959) los postulados tradicionales del Realismo son socavados para resultar en una estética propia que renovará el canon de la narrativa latinoamericana.

\section{ABSTRACT}

In this paper we aim to develop the category of the narrators' relay in the writing of the uruguayan Juan Carlos Onetti from the analysis of the procedures applied in three of his stories of the decade of ' 50 . On the basis of these narratological instances ("El álbum", 1953; Los adioses, 1954; y Para una tumba sin nombre, 1959) the traditional postulates of the Realism are undermined to result in an own aesthetics that will renew the canon of the Latin-American narrative. 
LA CITA DE JUAN CARLOS ONETTI que transcribimos de su cuento "El álbum" (I953) es bastante elocuente por varios motivos. En su extrema condensación, tiene la fuerza de aludir a tres componentes básicos de la narrativa onettiana en su afán de socavar al realismo clásico, minarlo u horadarlo a partir de ciertos procedimientos narratológicos, nudo de nuestra lectura crítica; ellos son: el destiempo de la historia respecto del relato (en el sentido genettiano ${ }^{\mathrm{T}}$ ) señala ya la fisura en la linealidad de la narración clásica; la naturaleza prologal de muchos de los relatos de Onetti es la marca de su carácter fragmentario que hace que una de las funciones del lector resida en tener que reconstruir la totalidad de la historia para comprenderla (muchas veces, porque el principio constructivo es el secreto, el lector no podrá determinar la verdad a partir de esa reconstrucción de los hechos por más completa que ésta sea); y, por último, y que se desprende de las dos características anteriores, es la sospecha de la imposibilidad de discernir sobre la verdadera historia. Estas tres maneras de dinamitar las certidumbres del realismo clásico, no son más que las maneras de narrar de Onetti, maneras que podríamos definir, casi barrocamente, como manieras en el sentido de un manierismo que, por muchas pistas estilísticas, son ya reconocibles en el arte de narrar del autor uruguayo. témporo-causal de los hechos descriptos y narrados) y el relato (récit, el orden que el narrador infunde en el acto de narrar la historia); ese singular orden del relato puede ser el de invertir, yuxtaponer, excluir hechos que serían imprescindibles desde la lógica del Cronos dominado por el principio de la sucesión témporo-causal. La narratología onettiana se basa en el proceso de ese desconcierto continuo, puesto que el lector deberá recomponer constantemente el nivel de la historia, debido a que se encuentra siempre desordenada, silenciada, supuesta, no-dicha. Véase Gérard Genette, Figures III. París: Ed. Seuil, I972. 
En este artículo nos disponemos a desarrollar una de nuestras hipótesis que se sitúa precisamente en el plano narratológico y que afecta a las categorías narrador y personaje. Se trata de los narradores concatenados que se pasan entre sí los datos y las informaciones sobre un hecho que termina volviéndose, de algún modo, un acontecimiento o representa, miniaturizada, la matriz del relato que éste desarrolla como ocurre de manera espectacular - espectacular porque es precisamente lo que el relato tematiza: su propio montaje y desmontaje de hechos; espectacular porque muestra los procedimientos y se jacta de su evidencia - en Una tumba sin nombre (I959) ${ }^{2}$ pero que podemos hallar en otros relatos como "El álbum” y Los adioses (I954) y otros escritos después de La vida breve en I950. Este pasarse información, de manera fidedigna o distorsionada, de un determinado hecho, constituye la cadena de versiones o, lo que podríamos definir como las versiones en cadena, las cuales, a diferencia del narrador omnisciente o quasi-omnisciente del realismo clásico, producen una interferencia irreversible respecto de la verdad de la historia.

Esta concatenación de versiones en cadena es lo que denominamos la posta de narradores porque la figura de la posta introduce la idea de un relevo, de una encadenamiento orquestado para que no se discontinúe: los distintos narradores parecen pasarse o batirse la justa y no importa ahora que el contenido de ese traspaso de información distorsione, al mismo tiempo, la misma; pero el modo de franquearse el dato es de boca a boca o manuscritamente (cartas, papeles), como si todavía estuviéramos en una época - y sobre todo en espacios - sin injerencia directa de los medios de comunicación. De allí que seleccionemos

2 En la primera edición de esta novela, este es el título original; a partir de I967 y en las ediciones sucesivas cambiará a Para una tumba sin nombre, como se lo conocerá habitualmente. Daniel Balderston (2009) anota, en la edición crítica de Archivos de las Novelas cortas, que Una tumba sin nombre puede tener que ver con el título del libro de Joaquín Torres García, Una ciudad sin nombre (I94I). 
la palabra posta como una instancia previa a la plena modernización mediática, los personajes nos remiten a formas aún artesanales para el intercambio de la información. En este sentido que venimos señalando, planteamos una fusión entre la categoría de narrador y la de personaje, ya que en algún momento de los tramos narrativos de la saga (ya sea en una novela, en una nouvelle o un relato) los personajes están llamados a volverse narradores, a tomar la palabra, son impelidos a escuchar un llamado: el de devenir narrador y contar lo que vieron o escucharon (o creyeron ver, o creyeron entender o interpretar de lo escuchado, etc.). Al respecto, cabe recordar que el narrador como categoría narratológica debe entenderse como inclusiva en la de personaje, es decir, todo narrador es, actancialmente, un personaje del relato que narra, lo que equivale a afirmar que todo personaje está ligado de alguna manera a la trama del relato que cuenta y en esto mucho tiene que ver, ciertamente, la elección de los puntos de vista narrativos para contar la historia.

Nuestro corpus de textos lo conforman los relatos inmediatamente posteriores a la aparición de La vida breve, texto núcleo donde aparece la ciudad imaginaria llamada Santa María, un espacio inventado que aparecerá de manera asidua en la obra narrativa de Onetti hasta la última novela publicada poco antes de su muerte, Cuando ya no importe (I993). De los relatos de la década del '50 elegiremos tres: "El álbum”, Los adioses y Para una tumba sin nombre pero no dejaremos de mencionar y analizar ciertos aspectos de los relatos restantes escritos en ese período tales como "Historia del Caballero de la rosa y de la Virgen encinta que vino de Liliput" (I956) y Jacob y el otro (I96 ${ }^{3}$ ), ambos escritos entre la publicación de las dos nouvelles recién mencionadas. Todas estas 
historias de los años cincuenta conforman, a nuestro entender, el laboratorio donde el escritor uruguayo cristaliza una poética definitiva y en su alquimia registra los procedimientos estilísticos que ulteriormente renovarán la narrativa latinoamericana.

“EL ÁLBUM” O LA PRIMERA VEZ

Promediando el cuento “El álbum”, escuchamos la voz de Jorge Malabia que dice: "Pero todo esto es un prólogo, porque la verdadera historia sólo empezó una semana después. También es prólogo mi visita a Díaz Grey, el médico, para que me presentara [...]" (Onetti, I994, I80). Este personaje estrena en el relato su capacidad de narrar, se adueña de la distribución del discurso inaugurando así su propio derrotero como personaje-narrador en el universo sanmariano. Malabia, "este chico de los Malabia, el menor", observa desde la puerta del periódico fundado por su propio abuelo a una llamativa - en Santa María cualquier injerencia extraña se volverá llamativa de inmediato, como en los casos de "Historia del Caballero de la rosa y de la Virgen encinta que vino de Liliput" o en Jacob y el otro, por ejemplo - mujer que camina por la ciudad. Esta elección narratológica en primera persona del singular queda acentuada desde el comienzo del relato a través de la explicitación del punto de vista espacial $y$ temporal: "la vi desde" son las tres primeras palabras del narrador que provee al lector la coordenada topográfica y apenas terminado el párrafo, el inicio del segundo aporta la información sobre la temporalidad: "Era un domingo de tarde húmedo y caluroso en el principio del invierno". De este modo, las historias sanmarianas transcurren - es una manera de decir, ya que en muchas de ellas el suceder de las acciones es meramente incidental - enmarcadas por principios y finales recurrentes. Una especie de temporalidad definida por la estaciones - por las cuatro estaciones - las surte de climas enrarecidos que 
responden más a los estados de ánimo de sus narradores que a la climatología in strictu sensu, leemos así cómo "los notables" narran en el comienzo de Para una tumba sin nombre aseverando que "es mejor, más armonioso, que la cosa empiece de noche, después y antes del sol"; o en La vida breve respiramos, dificultosamente, la inminencia de la tormenta de Santa Rosa al límite de un 30 de agosto que anunciará la primavera; y otras tantas aperturas y clausuras de otoños, inviernos y veranos funcionales a transmitir sensaciones vitales y agobiantes desde los narradores-personajes hacia los lectores de la saga ${ }^{4}$

Tiempo y espacio, los dos elementos que forman parte del cronotopo narrativo, son los dos ejes insustituibles de las narraciones clásicas que son vertidos desde el inicio por este narrador primerizo, dubitativo, que usa y abusa de la conjunción disyuntiva "o" menos por falencia informativa que por elección de estilo. Remitimos a los ejemplos, siempre en "El álbum”: "Al día siguiente, de mañana, pensé que Vázquez había mentido o exagerado, o que la mujer ya no estaba en Santa María." (Onetti, I994, I76); un poco antes: "Ella venía del puerto o de la ciudad [...]" (I75); después: "Estaba seguro de que la mujer había sido rechazada o disuelta por la imbecilidad de Santa María simbolizada con exactitud por los artículos de mi padre [...]" (I77); y así, de manera continua. Estas disyunciones se conjugan con una cuidadosa selección de adverbios acaso, quizá, tal vez - para lograr un pleno efecto de ambigüedad en este relato en cuestión, pero a esta altura del cuento - concretamente en la página seis de las catorce que lo componen - el narrador nos implica en el "verdadero" 
comienzo, el de la cita inicial: "Pero todo esto es un prólogo, porque la verdadera historia sólo empezó una semana después. También es prólogo mi visita a Díaz Grey, el médico, para que me presentara [...]”.

La historia contará el encuentro repetido y furtivo entre Jorge Malabia y la misteriosa mujer, Carmen Méndez, en una de las habitaciones del hotel. En cada uno de esos en cuentos el "hambre" sexual se satisface y entremezcla con otra pulsión oral primigenia, y también interactiva: la de relatar historias a un oyente, alguien le cuenta algo a otro. La mujer toma prestada, de manera explícita, la posta narrativa sólo por unas líneas, las suficientes para que Jorge Malabia, convertido en un alucinado escucha, asimile de manera lenta pero inexorable la primera lección:

No pude sospechar, ni siquiera cuando llegó la palabra Escocia, qué era lo que estaba iniciando: la voz caía suave, ininterrumpida, encima de mi cara. Me explicó que sólo es lluvia la que cae sin utilidad ni sentido (Onetti, I994, I82).

Sólo es lluvia la que cae sin utilidad ni sentido, es decir, una suerte de máxima estética que sobrevuela en el relato por sobre todas las cosas, lo cual equivale a un relato sostenido en la futilidad de lo bello antes que en la funcionalidad de lo necesario. Y evidencia el ansia apremiante del debutante - sexual y oral al mismo tiempo - por asimilar de la mujer enigmática la multiplicidad de técnicas, posturas, inflexiones, posiciones correspondientes a los dos - o acaso por qué no a uno solo - campos semánticos isotópicamente conectados entre el mundo de lo sexual y el mundo de lo oral. Lo que nos lleva a pensar que hay una dimensión erótica en la concepción narrativa onettiana, más allá de que tematice esta cuestión: en el más acá formal, sus relatos articulan eros y oralidad; quizás en este cuento específicamente se torne más verificable que en otros al tratarse de una historia de iniciación, el relato parece engendrarse en 
una escena de sexo oral que no se describe: la iniciación sexual y narrativa se fundamentan en la oralidad en su doble registro: la fonación del habla (la boca) y la recepción de la escucha (el oído).

Desde esta perspectiva, la relación sexual lo desvirga como narrador, y como en toda iniciación (los malentendidos del debut que deviene, por tanto, ensayo), el sujeto se deja hacer. Como una profesional del relato, como una Scherezade de la modernidad, la mujer (Carmen Méndez) cuenta y cuenta, hace y hace, explicitando modos y sugiriendo sutilezas mientras lo traslada por Egipto, California, Ruan, San Pablo; después, la mujer se marcha. Malabia, al fin y al cabo un muchacho de corta edad/ experiencia, hace caso omiso del sano consejo del visitador médico que le sugiere que la olvide y siga adelante; consigue dinero suficiente para retirar el baúl que la mujer dejó en el hotel como prenda por su deuda. Será con la ayuda y complicidad de Tito Perotti, otro joven - aunque menos prolífico - narrador sanmariano, que descubra en el interior del baúl del sarcófago, del espacio vacante aunque esta vez con contenido - la serie de fotografías que "hacía reales, infamaba cada una de las historias que me había contado, cada tarde en que la estuve queriendo y la escuché” (Onetti, I994, I88, cursivas nuestras).

LOS ADIOSES O LAS CONTINGENCIAS DE LA NARRACIÓN

Quisiera no haber visto del hombre, la primera vez que entró en el almacén, nada más que las manos; lentas, intimidadas y torpes, moviéndose sin fe, largas y todavía sin tostar, disculpándose por su actuación desinteresada. Hizo algunas preguntas y tomó una botella de cerveza, de pie en el extremo más sombrío del mostrador, vuelta la cara - sobre un fondo de alpargatas, el almanaque, embutidos blanqueados por los años hacia fuera, hacia el sol del atardecer y la altura violeta de la sierra, mientras esperaba el ómnibus que lo llevaría a los portones del hotel viejo (Onetti, 2009 [I954], 35). 
Reproducir íntegramente el primer párrafo de Los adioses no sólo conlleva reiterar la justiciera frase que Saer - a pocos años de su muerte, más vale tarde que nunca - dijera sobre éste: "todos los aspirantes a escritores de nuestra generación sabíamos de memoria" (Saer, 2006, 247); también intenta dar cuenta de otra observación del escritor santafesino respecto de la obra de Onetti. Dice Saer:

El narrador por ejemplo, en casi todos sus textos, más allá de las académicas atribuciones del punto de vista, siempre tiene una posición, una distancia, una capacidad de percibir y comprender respecto de lo narrado que es diferente cada vez y únicamente válida para el relato al que se aplica (Saer, 2006, 246).

En Los adioses el narrador innominado, el almacenero de esa ciudad serrana cordobesa, también innominada como la zona saeriana que sabemos alude a Santa Fe pero nunca la nombra5, es el encargado de la posta de correos entre los lugareños y el correo de la ciudad capital. A su vez, contiene y dispersa de manera cabal esos atributos enumerados por Saer, inviste al relato de una modalidad única que resiste hasta hoy una extensa andanada de lecturas hermenéuticas que han procurado resolverlo. Es, creemos, precisamente en ese narrador - también expresado en primera persona singular como en "El álbum" - donde se asienta - o se acuesta, en términos onettianos - la potencia indevelada de esta historia.

5 Sólo anotamos al pasar que los nombres de ciudades inventadas son significativos: el de Onetti es Santa María y el de Saer, si bien no es estrictamente una ciudad inventada, sí un espacio literario, con cierta autonomía, desde el momento en que decide ponerlo al margen de la nominación pero cuyas precisiones descriptivas señalan la ciudad de Santa Fe. Ambas parecen heredar los nombres de sus fundaciones desde la Colonia española: Santa María y Santa Fe. Estos resabios nominativos responden a un interés por la historia y por la manera en que estas ciudades fueron lanzadas a la realidad americana. Incluso el alter ego de la saga saeriana se llama significativamente Pichón Garay, el apellido de quien fundara por segunda vez la ciudad de Buenos Aires. 
Hay - instaurado asimismo en la historia literaria rioplatense - otro personaje que es testigo inmóvil y sólo puede percibir postrado desde su catre y por fragmentos, entre los barrotes de la ventana y a través de las paredes del rancho que amortiguan los sonidos: el pulpero Recabarren, del cuento "El Fin" de Jorge Luis Borges.

"Fuera de un personaje, Recabarren, cuya inmovilidad y pasividad sirven de contraste [prologa Borges en I944] nada o casi nada es invención mía [...] todo lo que hay en ['El Fin'] está implícito en un libro famoso y yo he sido el primero en desentrañarlo o, por lo menos, en declararlo" (Borges, I956, II5-II6).

De forma legítima, o falsa modestia mediante, Borges ha individualizado su aporte.

Tan minusválido como el testigo borgiano, el narrador onettiano lleva doce años "arreglándose con tres cuartos de pulmón” y durante toda la historia abandona las inmediaciones del mostrador apenas en tres o cuatro circunstancias. Desde su centro, recompone y reactualiza los chismes y cuentos del enfermero o las mucamas del viejo hotel; recibe y adivina a partir de letras y envoltorios la correspondencia para el basquetbolista enfermo; observa y conjetura sobre los arribos y partidas de las dos mujeres implicadas en la historia.

El movimiento que se produce genera una constante tematización del verbo saber y podemos observar numerosos párrafos encabezados de las siguientes maneras: "Supe por el enfermero [...]" (Onetti, 2009, 37), "Nunca supe [...]" (40), “¿A qué no sabe? (4I), “Él sabía, [...]” (47) “No sé [...]” (57), etcétera. En esta cadencia inacabable entre la certeza y la incertidumbre, la única seguridad brota del principio del relato: de manera quiasmática el narrador nos otorga temprano - en la segunda página - el seguro, inflexible, devastador epílogo: "No es que crea imposible curarse, sino que no cree en el valor, en la trascendencia de curarse" (Onetti, 2009, 37). 
Justo antes de atestiguar el resultado del desenlace impostergable, el narrador descubre el "poder" de la palabra escrita, encuentra olvidadas un par de cartas en "el fondo del cajón de la correspondencia" - una vez más un espacio/ fondo a ser llenado por la representación gráfica, como vimos con el baúl y las fotografías en "El álbum" -, y decide emprender su lectura. Ante la opción de "anteponer mi reciente descubrimiento al principio de la historia, para que todo se hiciera sencillo y previsible" el almacenero quema las cartas, anula la fijación del relato e inmediatamente declara su posición de narrador que escatima los datos al resto de los personajes; sólo el lector podrá conocer el contenido de las mismas. Sin embargo, relativiza la potestad absoluta del narrador omnisciente clásico cuando otorga al lector todos los elementos que posee pero no intercede directamente en su interpretación o, aún mejor, interpreta primero y se desdice luego: "Porque suponiendo que hubiera acertado al interpretar la carta, no importaba, en relación a lo esencial, el vínculo que unía a la muchacha con el hombre. Era una mujer, en todo caso; otra" (Onetti, 2009, 76).

En el estudio introductorio del primer tomo de las Obras Completas de Juan Carlos Onetti editadas por Galaxia Gutenberg (2005), el escritor mexicano Juan Villoro sopesa agudamente las novelas que se encuentran comprendidas entre I939 y I954, es decir, de El pozo a Los adioses. Ya en el análisis de Tierra de nadie (I94I), plantea la misma como una novela "de voces, no de gente" en la cual los acontecimientos - las acciones - son continuamente relevados por otros, y destaca a la "interrupción" como el recurso más importante cuando "el narrador practica cortes cinematográficos y yuxtapone escenas" (Villoro, 2005, 4). El ensayista percibe con sagacidad esta historia como la única onettiana en la que

6 Es curioso, luego de relacionar el narrador almacenero de Los adioses con el personaje Recabarren de "El Fin”, reparamos en la similitud de estas líneas de Onetti con las magistrales de Borges al finalizar su cuento: "Cumplida su tarea de justiciero, ahora era nadie. Mejor dicho era el otro: no tenía destino sobre la tierra y había matado a un hombre" (cursivas nuestras). 
los personajes tienen prisa y deambulan arrastrados por la vorágine metropolitana de Buenos Aires. Dentro de este torrente Villoro identifica con precisión el procedimiento de escritura:

Para un narrador que suele depender de la incomprensión, nada podía ser tan formativo como un tejido de voces múltiples, sueltas, simultáneas, que no siempre se escuchan entre sí y el autor convierte en discurso unitario (Villoro, 2005, 4, cursivas nuestras).

En la década del '5o los personajes habitan en la tranquilidad provinciana o en la quietud pueblerina, desde allí postean el discurso y relevan las voces, no ya los hechos. En lo sucesivo a La vida breve, por lo general, un único bloque de sentido basta para dar cuenta de la materia de cada historia: la primera experiencia de Jorge Malabia en "El álbum"; la agonía del basquetbolista en Los adioses; el retorno a Santa María de Larsen-Junta en El astillero (I96I); la instalación del prostíbulo en Juntacadáveres (I964). Las historias tratan de un mismo acontecer que puede reducirse a la mínima expresión o germinal matriz: contar el cuento, según Ludmer (I977), para nuestra próxima novela.

\section{PARA unA TUMBA SIN NOMBRE O EL PAROXISMO DE UNA ESTRATEGIA}

Todo eso sabemos. Todos nosotros sabemos cómo es un entierro en Santa María, podemos describirlo a un forastero, contarlo epistolarmente a un pariente lejano. Pero esto no lo sabíamos; este entierro, esta manera de enterrar.

Empecé a saberlo, desaprensivo, irónico, sin sospechar que estaba enterándome,[...] (Onetti, 2009 [1959], 84).

El quiebre furibundo de las personas de la narración - se transfiere de un plural mayestático Nosotros, los notables, a la primera singular empecé - da 
cuenta en este relato, apenas iniciado, de que nos encontramos ante una estrategia particular en el acto de contar. Ya en La vida breve, al término del capítulo cuatro "La salvación”, Brausen se transfigura - en el mismo párrafo - en Díaz Grey sin mediar explicaciones, lo realiza continuando el relato en primera persona singular. Luego, de inmediato, en el capítulo cinco "Elena Sala" la narración en primera persona singular se traslada sin esfuerzo hacia la tercera singular: “- Por favor, un minuto. Puede sentarse - dije sin mirarla. Me incliné sobre el escritorio para anotar en la libreta un nombre y una suma de dinero, después el médico, Díaz Grey, se acercó con frialdad a la mujer que no había querido sentarse" (Onetti, I968, 38, cursivas nuestras).

A partir de esta primera anomalía - naturalizada con evidente maestría técnica -, una y otra vez, durante los seis apartados que conforman Para una tumba sin nombre los narradores compaginan sus voces acompasadamente. El médico, Jorge Malabia, el comisionista Godoy, Tito Perotti y Rita generan los relatos entre diálogos, escuchas, parlamentos remedados o escrituras en el papel. Unos a otros prestan boca, oídos y ojos (no olvidemos que Jorge Malabia lee lo que “adivina” y transcribe el médico sobre Ambrosio, el proxeneta perfeccionador) para materializar las diferentes versiones de los hechos y hasta la negación de la existencia de los mismos. Lo interesante, percibimos, es cómo lo hacen mediante expresas indicaciones, por momento instrucciones, que se asemejan a un protocolo de lectura: "A partir de aquí la historia puede ser infinita o avanzar sin descanso, en vano, hacia el epílogo en el cementerio. Creo que faltan pocas palabras, que pueden distribuirse así, entre todas estas cosas: [...]" (Onetti, 2009, III, cursivas nuestras), escribe el médico; “Todo esto, ya sé, no importa, nada tiene que ver con el chivo. Lo cuento porque de esto deriva otra importancia: la que tuve que darle, un poco a espaldas de Tito, al relato de Godoy, el comisionista, sobre su encuentro en Constitución con Rita” (97), dice Jorge Malabia; “No le ordeno fijarse en esto o en lo otro; se lo sugiero, simplemente. Cuando 
le pido que se fije en algo no lo ayudo en nada a comprender la historia; pero acaso esas sugerencias le sean útiles para aproximarse a mi comprensión de la historia, a mi historia” (99), impela Malabia al doctor.

Y, finalmente: "Rabiosos y humillados porque él (Godoy) había puesto, antes que nosotros, las puercas manos, la puerca voz en la historia de Rita y el chivo" (Onetti, I994, 94), repite Malabia y certifica con su antes que nosotros el indefectible juego de postas, donde aquellos que tienen la posibilidad de escuchar - “el vicio más mío, más intenso, más rico” diría el primerizo Jorge Malabia de "El álbum" - siempre se transfiguran en relatores. Víctimas de una pulsión oral incontenida, esclavos del mandato primigenio antes mencionado, los personajes de Onetti se convierten en narradores concatenados que transfieren los datos potenciando una cadena de versiones que encuentra su paroxismo en Para una tumba sin nombre.

En esta dirección, trabajamos teórica y críticamente en la configuración de un sistema narrativo consistente en lo que hemos dado en llamar una posta de narradores, procedimiento que se lleva a cabo por parte de los narradorespersonajes 7 recurrentes del universo onettiano.

Además, esta hipótesis - la de la posta de narradores - se refuerza directamente en otros dos relatos, "Historia del Caballero de la Rosa y de la Virgen encinta que vino de Liliput", de I956, y Jacob y el otro, publicado en i96I. Ambas narraciones comparten con Para una tumba... el esqueleto estructural una cadena de versiones o de versiones en cadena: como sucede con Los adioses o Para una tumba sin nombre, entre otros textos) se sostiene en otra hipótesis de trabajo que manejamos: todos los personajes de Onetti están llamados a volverse narradores en algún momentos de los tramos narrativos de la saga. Como ya hemos mencionado en las primeras páginas de este trabajo, sabemos desde los estudios de la Narratología contemporánea que todo narrador es, en verdad, un personaje perteneciente a la trama narrativa; lo que planteamos es que los personajes de Onetti se convierten en algún momento dado en narradores, es decir, toman la palabra para narrar. 
segmentado en seis apartados que no analizaremos en detalle - por razones de tiempo y/o espacio, para seguir en tren de términos narratológicos - pero sí a nivel paratextual ${ }^{8}$ para intentar denotar el flujo intersubjetivo, de uno a otro personaje narrador, de la información.

Por un lado, "Historia del Caballero..." se divide en seis partes, como ya dijimos, numeradas correlativamente; la primera persona plural narra todos los estadios y se expresa en un plural mayestático - otra vez los notables de Santa María - que se descompone en tres voces autorizadas. A saber: Díaz Grey, el médico; Guiñazú, abogado y escribano; el viejo Lanza, encargado de la corrección de pruebas de El liberal, el periódico sanmariano, y de casi cualquier otra cosa a ser impresa en la ciudad. Los tres personajes construirán desde sus informaciones parciales el relato una vez más formateado por Díaz Grey, claro que teniendo en cuenta los emisores del discurso - médico, abogado y corrector de pruebas, o sea, tres tradicionales representantes de la validación de la palabra escrita - las versiones son más armónicas y menos disímiles que en Para una tumba..., aunque a fin de cuentas - nuevamente Onetti subvirtiendo los modelos - el resultado es el mismo de siempre: cito el momento final cuando el Caballero acumula las ofrendas florales compradas con los quinientos pesos heredados de Doña Mina "hasta levantar la montaña insolente y despareja que expresaba para él y para la muerta lo que nosotros no pudimos saber nunca con certeza” (Onetti,I994, 2II).

Haciendo uso de la excepción que hace a la regla - por la constricción paratextual antedicha - ejemplifico sólo una vez con el interior del texto. Durante

8 Cfr. Genette, Gérard, Seuils. Paris: Ed. du Seuil, I987. Remitimos a las máximas teóricas de Genette para corroborar la importancia de los elementos paratextuales habituales (títulos, subtítulos, índice, etcétera); y en el caso específico de Onetti sostenemos una preocupada elaboración por parte del autor en este sentido. Por ejemplo, en la cuidadosa e intencionada elección de los nombres de cada capítulo de La vida breve: muchos de estos sintagmas complementan o posibilitan la comprensión del lector respecto del contenido de cada apartado. 
el apartado tres de "Historia del Caballero..." se expresa - otra vez el narrador innominado en primera persona plural deviene en singular - ante la desaparición momentánea de la extraña pareja:

Y, en seguida, una pausa en la que los creímos perdidos para siempre, en la que describimos con algún ingenio su arribo a cualquier otra ciudad costera, confiados y un poco envanecidos, un poco displicentes [...] Pero nunca nos pusimos de acuerdo.[...] Y me empeñé en oponer a todas las teorías soeces una interpretación teológica no más absurda que el final de esta historia. (Onetti, I994, I94, cursivas nuestras)

Queda demostrado: son personajes que no pueden dejar de narrar, aún basados en la ignorancia y el desconocimiento pergeñan teorías soeces para rellenar el vacío que provoca la ausencia de los curiosos extranjeros. En el exhaustivo análisis de los cuentos, artículos y misceláneas que desarrolla Pablo Rocca - en el "Prólogo" al tercer tomo de las obras completas mencionadas ut supra - corroboramos lo antedicho; el especialista considera que para Onetti no es necesario saber a fondo una historia para contarla ya que

[...] [L]a multiplicación de voces narrativas en un mismo relato abre otra posibilidad a la habitual interpretación de que los narradores de Onetti tienen la paradójica convicción de que es posible contar lo que no admite una explicación contundente [...] al fin y al cabo todo consiste en contar [...] el mundo, los seres y las cosas adquieren algún sentido provisorio si se someten al arte de narrar (Rocca, 2009, Prólogo, XXXV, cursivas nuestras),

y, ya inmersos en el arte de narrar, coincidimos con Villoro cuando asevera que “Onetti depende de la forma en que narran sus personajes" (2005, I).

Por otro lado, pero del mismo modo, Jacob y el otro escande su derrotero narrativo en seis instancias no sólo numeradas sino subtituladas en cursiva, 
leáse destacadas ex profeso de la homogeneidad del cuerpo principal del texto. El apartado número dos - y se infiere extensivamente para el tres, el cuatro, y el cinco - es encabezado por la leyenda Cuenta el narrador, donde una tercera persona relata sin intervenciones ajenas el nodo fundamental de la estancia de los dos desconocidos en Santa María antes del combate que protagonizará Jacob. El parágrafo número uno se antecede con la leyenda Cuenta el médico, en el cual, en una primera persona del singular, el narrador da cuenta de la intervención médico-quirúrgica al derrotado de la lucha para terminar aceptando que "nunca podría conocer la verdad de aquella historia, con buena suerte y paciencia tal vez llegara a enterarme de la mitad correspondiente a nosotros, los habitantes de la ciudad" (Onetti, I994, 260). Y, finalmente, en el fragmento número seis subtitulado Cuenta el príncipe, Orsini cuenta en primera persona el desenlace de la pelea y nos enteramos de la verdadera identidad del politraumatizado inicial.

El relato surte total efecto por la estudiada concatenación de sus partes, el montaje como procedimiento opera a pleno y aun cuando el lector conoce la completitud de lo recorrido, verificamos que algunos personajes-narradores se han quedado a mitad de camino - como el médico -, han agotado la totalidad de su energía para cumplir con su mandato ineludible, entregar, en tiempo y forma, la posta del discurso al resto de sus congéneres.

SOBRE ALGUNAS CONSIDERACIONES ACERCA DEL ARTE DE NARRAR EN ONETTI

Ya establecido un triple movimiento para la escritura onettiana, es decir, parangonados tres momentos de caracterización en un corte determinado de su narrativa: el primer intento (la iniciación o el ensayo), la formación o contingencia y el paroxismo, resta dar cuenta explícita de lo que entendemos como el proceso completo del devenir de sus personajes-narradores. Por consenso crítico 
conocemos la clásica escisión de la obra de Onetti como pre y pos Santa María, con La vida breve de I950 irrumpe en la narrativa latinoamericana la primera ciudad inventada. Es a partir de la construcción concreta de este espacio mítico cuando algunos de los personajes que protagonizan la fase inicial de la escritura de Onetti - hasta aquí una nouvelle, dos novelas y doce cuentos - validan su existencia transmigrante ${ }^{9}$ y comienzan a referir y circular historias entre sí que remiten de modo metarreferencial al universo sanmariano. Por esto mismo, proponemos la década del '5o en toda su extensión - dos novelas, un relato y los tres cuentos mencionados - como el campo de pruebas y consecución de una de las exploraciones más logradas por Juan Carlos Onetti: la constitución de sus personajes-narradores.

9 Consideramos el concepto de saga narrativa como un locus imaginario cuyos habitantes se vuelven transmigrantes del universo ficcional, lo cual crea la ilusión de que esos personajes parecen vivir más allá de la ficción, esto es, en los intersticios existentes entre un libro y otro (Cfr. Lukács "Balzac: Los campesinos" en Ensayos sobre el realismo, I965). Como ejemplo del impacto de la aparición de Santa María como bisagra dentro de la poética de Onetti consideremos - por ahora sólo dos - los siguientes casos: I) En I94I en la novela Tierra de nadie un cafisho llamado Larsen recorre la ciudad de Buenos Aires confundido con el resto de los personajes; en I950 en La vida breve su presencia, sin ser ni siquiera nombrado, ocupa apenas una escena en casi trescientas páginas; más tarde, en I96I protagoniza como Larsen/Junta la epopeya perdida de antemano de la refuncionalización de $E l$ astillero y muere. En I964 se cuenta Juntacadáveres - cronológicamente anterior a El astillero - : Jorge Malabia relata cómo Junta intenta instalar el prostíbulo en Santa María y es finalmente expulsado de la ciudad en una escena que - prestidigitación excelsa de la narración - ya fue relatada catorce años atrás en La vida breve. 2) El 3 de abril de I949 Onetti publica en La Nación el suelto "La casa en la arena", allí localizamos prefiguradamente al doctor Díaz Grey y otros rasgos constitutivos de lo que se nominará como Santa María al año entrante. Como estilaba por esa época, Onetti decide publicar por anticipado este fragmento de La vida breve. Sin embargo, luego lo recortará y quedará excluido del universo sanmariano junto con un personaje pirómano y violento muy curioso apelado el Colorado. Casi como una revancha por motus propio, el Colorado irrumpe en la saga en I979 (itreinta años después!) como el incendiario que inicia la devastación en Dejemos hablar al viento. Último dato extra: en Dejemos hablar al viento un Larsen agusanado resucita de su muerte entre paréntesis - lo de los paréntesis es literal, remito al final de Juntacadáveres - y conversa tranquilo con el comisario Medina. 
Jorge Malabia, adolescente cuasi imberbe en "El álbum", absorbe y transmuta la fantástica capacidad oratoria de Carmen Méndez y aporta su versión desencajada en Para una tumba sin nombre. Acaso haya estado estudiando su lección estética tumbado en la cama junto a Rita y el chivo - los personajesnarradores se encuentran casi siempre tumbados elucubrando hipótesis - para producir historias que ocupen la vacancia del ataúd vacío que propone Foffani en "Los funerales del Realismo":

\footnotetext{
Un juego envolvente, un juego que impregna, un juego que contagia a los distintos narradores, como si el acto de narrar fuera una enfermedad: el contagio consiste en narrar sea como sea, faltando a la verdad o urdiendo "deliberadas mentiras". A través del proceso de alegorización, que el barroquismo de la composición permite instalar en diversas escenas, lo que finalmente se entierra en esa tumba sin nombre es la estética realista (Foffani, 2009, mimeo).
}

Si el cadáver es el Realismo, entonces surgirá de inmediato el fantasma del mismo - todo muerto, Foffani lo dice, "no termina nunca de morir" - como resquicio técnico, como red de aristas o cabos que amarran la embarcación - la poética de Onetti - para impedir la deriva o el posible naufragio en los registros fantásticos o metafísicos que pululan contemporáneamente en el Río de la Plata. Como propusimos en el comienzo de este artículo Onetti monta y desmonta, socava y restituye, subvierte y reformula un abanico de procedimientos escriturarios en pos de imponer su singularísima relación con el Realismo tradicional sin intenciones expresas de anularlo.

A esta altura de su existencia, Malabia no volverá a cometer el inicial error. Sabe que hay que alejarse de la clausura del relato, del feroz anclaje que proporciona la imagen, la desgarradora visión de las fotos, recordemos "El infierno tan temido" (Onetti, I957). Él, con seguridad - la seguridad que le otorga el 
médico, imprescindible narrador sanmariano, cuando en Para una tumba... lo reconoce como uno de su "propia raza” -, no volverá a abrir ese baúl.

El almacenero de Los adioses, estático y pendiente de lo que suceda a su alrededor se conforma con la desaparición de la evidencia - Panesi (I997) y Ludmer (I977) ya lo han sindicado como el relato antipolicial por excelencia -, mezquina la información al prosaico juicio de los personajes chismosos y habladore ${ }^{10}$ como el enfermero o la mucama del hotel, y reclama la variable complicidad del lector. Conocedor consciente, no por ciencia sino por intuición, del destino final de sus objetos/sujetos de narración - experto diagnosticador de resultados finales sobre tuberculosos -, el almacenero quema las cartas luego de des/interpretarlas abriendo el abanico inabarcable de posibilidades ante los estupefactos ojos del lector de turno.

El médico y sus congéneres, Malabia adulto, Godoy, Perotti, todos ellos actores indispensables del teatro sanmariano, conocen a la perfección el caos organizado o la "fisonomía del desorden" (Villoro, 2005) que rige el universo de Juan María Brausen; saben que invariablemente deberán desempeñar el rol que DiosBrausen les arroje en suerte, por eso, mientras pueden: inventan y amontonan historias, sus historias, unas sobre otras en un aceitado sistema de postas, sin cesar, hasta que como la serpiente Ouroboros ${ }^{\mathrm{II}}$ terminen por morderse la cola. Aporta Verani:

Cuando se está a punto de aceptar como verdadera la historia referida, surge una nueva variante que destruye la ilusión de realidad e incita a que el lector asuma la

Io Aquí diferenciamos claramente entre personajes narradores/relatores/contadores como los hemos caracterizado hasta ahora y habladores o chismosos que sólo tienen por función el aporte aislado de la información y no el relato de lo percibido.

II Serpiente que comprende e implica también las ideas de movimiento, continuidad, autofecundación, renovación, regeneración, recreación. Conceptos que abonan de manera intrínseca la cadena ilimitada de versiones que postean los emisores. 
responsabilidad de recomponer el relato en busca del sentido unívoco del universo representado (I98I, 44, cursivas nuestras).

Y, luego, el mismo crítico completa: “Todos los actantes participan, de alguna manera, de la creación, de la invención, tratan de subsistir asumiendo una responsabilidad, con el énfasis siempre en mi historia, nunca en la historia" (Verani, I98I, 5I).

Desde la radicalidad de sus procedimientos, Onetti atempera y gradúa la eficacia de sus elecciones estilísticas en busca del molde mejor adecuado a su concepción de storyteller. La figura del contador de cuentos atraviesa de manera expresa la obra del autor uruguayo en relación con los pioneros y maestros del género en la narrativa norteamericana. Víctor Suaid - protagonista del primer cuento de Onetti “Av. de Mayo- Diagonal- Av. de Mayo”, La prensa, I933 - camina durante doscientos metros, en un ir y venir entre las calles del título, localizadas en pleno centro porteño, en pos del encuentro con una mujer. Mientras tanto, divaga con su imaginación y deja entrever en la narración fabulosas andanzas de rústicos hombres barbudos, revólveres de la Policía Montada y aserraderos a orillas del Yukón, en las nieves de Alaska y con la expresa mención nada menos que de Jack London. En su tercer cuento - "El posible Baldi”, La Nación, I936 - Onetti instaura a Baldi, un ignoto abogado que cuenta de manera compulsiva historias extraordinarias a las "Bovary de Plaza Congreso". En sus relatos no faltan empalizadas de fortificaciones militares sobre el río Colorado, el indio Caballo Blanco, jefe de los sioux, o Buffalo Bill, como representantes de los nodos fundacionales de los cuentos del Lejano Oeste, primigenio territorio generador de historias. En lo que respecta a los más consagrados relatores de la escuela norteamericana la muy estudiada relación con el universo de William Faulkner basta como muestra del modelo implícito. Y también pueden agregarse correspondencias con John Dos Passos o Ernest Hemingway. 
Los personajes de Onetti en su múltiple pulsión narrativa - ser narrados, ser escuchas, tornarse lectores, procesar las versiones, verterse como narradores - están munidos de ciertas características que colindan con el campo semántico propio de la posta, en su significado más literal y en los sentidos que despliegan sus acepciones más figurativas. No de otra modo puede interpretarse la insistencia (Jorge Malabia se esfuerza y reúne el dinero para conseguir abrir el baúl que le aconsejaron no tocar), la diligencia (el almacén es literalmente la posta de correos de la localidad serrana), la intencionalidad (todos quieren versionar en Para una tumba...), la apuesta y el riesgo (el luchador Jacob y su desafiante politraumatizado), el recordatorio (los quinientos pesos en flores que deposita el Caballero sobre la lápida de Doña Mina o las fotos de "El álbum" o las que contempla anonadado Risso en "El infierno tan temido") ${ }^{\text {I2 }}$ que formatean las acciones de los habitantes sanmarianos en la prolífica década de los años cincuenta.

Las múltiples voces inundan a la manera de un delta desbordado el territorio mítico recién inaugurado: en sus primerizos devaneos operan por ensayo y error; luego, en su divergencia, el caprichoso cauce alcanza incontenible el poblado serrano para afrontar y resolver la contingencia; más tarde, ya reencauzados en Santa María, surtidos caudales arrecian contra las piedras erosionadas de la mímesis realista en un paroxismo desenfrenado. Operando con su diccionario online: posta (Del it. posta). I. m. Persona que corre y va por la posta a una diligencia, propia o ajena. 4. $\mathrm{f}$. En los juegos de envite, porción de dinero que se envida y pone sobre la mesa. 5. f. Tarjeta grande con un letrero conmemorativo. 6. f. Conjunto de caballerías que se apostaban en los caminos a distancia de dos o tres leguas, para que los tiros, los correos, etc., pudiesen ser renovados. 7. f. Casa o lugar donde estaban las postas. 8. f. Distancia que había de una posta a otra. / a . I. loc. adv. coloq. adrede. / $a$ su . I. loc.adv. ant. A su propósito, a su voluntad./ irse un enfermo por la . I. loc. verb. coloq. Estar a punto de morir. /por la .I. loc. adv. Corriendo la posta. 2. loc. adv. coloq. Con prisa, presteza o velocidad. 
sus personajes- narradores, Onetti resulta airoso en cada uno de los embates, al sistematizar el relevo de las versiones codifica un sistema que pondrá en práctica y extremará en posteriores relatos. Lo que proponemos y denominamos aquí posta de narradores se convierte en la fractura y descomposición definitiva del narrador omnisciente típico en una serie de versiones, ya no la única verosímil sino múltiples enunciados del mismo hecho. Estos narradores, desde la diversidad de sus relatos, anulan, desmontan, desrealizan al supuesto unívoco o verdadero, o en palabras del médico: “[convierten] en victoria por lo menos una de las derrotas cotidianas" (Onetti, 2009, I3I).

REFERENCIAS BIBLIOGRÁFICAS

Borges, Jorge Luis, “El fin”. Ficciones. Buenos Aires: Emecé, 1956.

Demarchi, Rogelio, Padre Brausen que estás en mi cama. Una excursión literaria a la Santa María de Onetti. Córdoba: Alción Ed, 2008.

Foffani, Enrique, "Los funerales del Realismo. Para una tumba sin nombre de Juan Carlos Onetti”. Actas del coloquio dedicado al centenario del nacimiento de J. C. Onetti. 2009 (Mimeo).

Genette, Gérard, Seuils. Paris: Ed. du Seuil, I987. Figures III. Paris: Ed. du Seuil, I972.

Ludmer, Josefina, Onetti: Los procesos de construcción del relato. Buenos Aires: Sudamericana, I977.

Lukács, Georg, Ensayos sobre el realismo. México: Siglo XX, I965.

Onetti, Juan Carlos, Cuentos completos. Madrid: Alfaguara, I994. La vida breve. Buenos Aires: Sudamericana, I968[1950]. 
, Novelas cortas. Córdoba: Alción Editora/Colección Archivos, 2009. Incluye Los adioses [1954] y Para una tumba sin nombre [I959], entre otras.

Obras completas. Edición de Hortensia de Campanella. Barcelona: Galaxia Gutenberg/Círculo de lectores, tres volúmenes, 2005/ 2007/ 2009.

Panesi, Jorge, "La lectura como adivinanza en Los adioses". Actas de las jormadas de homenaje a J. C. Onetti. Montevideo: UdeLaR, I997.

Rocca, Pablo, "Prólogo" a Obras completas de Juan Carlos Onetti. Tomo I. Barcelona: Galaxia Gutenberg/ Círculo de lectores, 2009.

Saer, Juan José, Trabajos. Buenos Aires: Seix Barral, 2006.

Villoro, Juan, “La fisonomía del desorden- De El pozo a Los adioses”. Obras Completas de Juan Carlos Onetti. Tomo III. Barcelona: Galaxia Gutenberg/ Círculo de Lectores, 2005. http://www.onetti.net/es/descripciones/villoro

Verani, Hugo, Onetti: el ritual de la impostura. Caracas: Monte Ávila, I98I. 